\title{
REVIEW: TES DIAGNOSTIK SEBAGAI TES FORMATIF DALAM PEMBELAJARAN KIMIA
}

\section{REVIEW: DIAGNOSTIC TEST AS FORMATIVE TEST IN CHEMICAL LEARNING}

\author{
Ellen Sutopo Putri dan *Rinaningsih \\ Jurusan Kimia FMIPA Universitas Negeri Surabaya \\ e-mail: $\underline{\text { rinaningsih@unesa.ac.id }}$
}

\begin{abstract}
Abstrak
Artikel dibuat bertujuan untuk mengetahui pengaruh penggunaan tes diagnostik sebagai tes formatif dalam meningkatkan hasil belajar pada materi kimia. Metode yang digunakan yaitu metode metaanalisis dengan cara membandingkan informasi beberapa studi literatur penelitian yang seragam. Peserta didik memiliki kemampuan belajar yang berbeda-beda, sehingga peran guru sebagai fasilitator sangat diperlukan. Guru harus mengetahui kemampuan awal peserta didik secara individu melalui kegiatan penilaian agar guru mengetahui kemampuan peserta didik. Informasi yang didapatkan dari peserta didik dapat digunakan sebagai rujukan dalam memperbaiki proses belajar. Keterlibatan tes diagnostik sebagai tes formatif dalam pembelajaran kimia digunakan sebagai pertimbangan pengetahuan awal untuk pembentukan kelompok heterogen, penekanan dalam pembelajaran, dan penentuan kesulitan belajar peserta didik yang dapat meningkatkan hasil belajar peserta didik. Penggunaan tes diagnostik sebagai tes formatif dalam pembelajaran kimia dapat memberikan diagnosis kesulitan belajar yang jitu. Berdasarkan analisis 3 literatur, tes diagnostik dapat meningkatkan hasil belajar peserta didik melalui pembentukan kelompok heterogen. Perencanaan pembelajaran dengan tes diagnostik sebagai pertimbangan dalam pembelajaran pembentukan kelompok tersebut menghasilkan peningkatan paling rendah sebesar 26,85\% dan peningkatan paling tinggi sebesar 38,9\%. Perbandingan peningkatan hasil belajar peserta didik dapat diamati melalui presentase hasil ketuntasan sebelum dan sesudah dilakukan tes diagnostikyang kemudian dilakukan uji statistik paired. Hasil belajar peserta didik dilihat dari presentase ketuntasan belajar sebelum dan sesudah menggunakan tes diagnostik yang kemudian diolah menggunakan uji statistik tipe paired sample. Uji tersebut menghasilkan rata-rata peningkatan hasil belajar yang signifikan sebesar $32,583 \%$. Hal tersebut menunjukkan hasil belajar peserta didik mengalami peningkatan setelah menggunakan tes diagnostik sebagai tes formatif pada pembelajaran kimia.
\end{abstract}

Kata kunci: Kimia, Tes Diagnostik, Tes Formatif

\begin{abstract}
The author's article aims to determine the effect of using a diagnostic test as a formative test in improving learning outcomes in chemical materials. The method used is the meta-analysis method by comparing information through several studies of uniform research literature. Students have different learning ability, so the role of the teacher as a facilitator is indispensable. Teachers must know the initial ability of students individually through early assessment activities so that teachers know the ability of students. The information obtained from students can be used as a reference in improving the learning process. The involvement of diagnostic tests as a formative test in chemistry learning is used as early consideration knowledge for the formation of heterogeneous groups, emphasis in learning, and determination of difficulty learning students that can improve student learning outcomes. The use of diagnostic tests as a formative test in chemistry learning can provide an accurate diagnosis of learning difficulties. Based on the analysis of 3 literature, diagnostic tests can improve student learning outcomes through the formation of heterogeneous groups. Learning planning with diagnostic tests as a consideration in the group formation learning resulted in the lowest increase of $26.85 \%$ and the highest increase of $38.9 \%$. The comparison increase in student learning outcomes can be observed through the percentage of completeness results before and after the diagnostic test is carried out, which is then carried out by paired statistical tests. Student learning outcomes are seen from the percentage of learning completeness before and after using a diagnostic test which is then processed using a paired sample type statistical test. The test resulted in a significant increase in learning outcomes of $32.583 \%$. This shows that student learning outcomes have increased after using diagnostic tests as a formative test in chemistry learning.
\end{abstract}

Key words: Chemistry, Diagnostic Test, Formative Test 


\section{PENDAHULUAN}

Kimia merupakan mata pelajaran yang memiliki kompleksitas yang cukup tinggi. Materi dalam kegiatan pembelajaran kimia sangat banyak dan saling berhubungan, sehingga apabila salah satu konsep materi tidak tertanam dengan kuat maka siswa cenderung akan mengalami kesulitan dengan konsep materi yang lain [1]. Hal ini karena pelajaran kimia memiliki tiga tingkat representasi kimia yang berbeda. Tiga tingkat representasi pada mata pelajaran kimia yaitu dimensi makroskopik, dimensi simbolik dan submikroskopik [2]. Pentingnya peserta didik dalam memiliki ketiga kemampuan representasi tersebut yaitu untuk menguasai berbagai level representasi dan menguasai dalam mentransfer serta menghubungkan berbagai level representasi [3].

Peserta didik merupakan individu yang memiliki karakteristik berbeda-beda terutama pada kemampuan belajar. Terdapat peserta didik yang cepat memahami yang telah diajarkan dan ada pula yang lambat serta memiliki hambatan dalam belajar, sehingga peran guru sebagai fasilitator sangat diperlukan. Salah satu usaha guru sebagai fasilitator yaitu dengan menerapkan pembelajaran kelompok agar peserta didik dapat ikut aktif dalam proses pembelajaran. Pembentukan kelompok yang digunakan oleh guru dapat berupa kelompok heterogen yaitu pembentukan kelompok berdasarkan kemampuan akademis peserta didik yang terdiri dari peserta didik berkemampuan akademis rendah, sedang, dan tinggi [4].

Guru sebagai fasilitator tidak bertindak sebagai pemberi informasi melainkan menunjukkan peserta didik yang lebih menonjol dalam pengajaran [5]. Guru sebagai fasilitator harus mengetahui kemampuan peserta didik secara individu melalui kegiatan penilaian agar guru bisa mengetahui kemampuan awal peserta didik. Pengukuran kemampuan peserta didik dapat dilakukan dengan mendiagnosis kesulitan belajar peserta didik secara individu [6].

Pada umumnya dalam mendiagnosis kesulitan belajar bisa menggunakan tes diagnostik dan tes formatif yang dilakukan sekaligus atau secara terpisah (secara khusus). Penggunaan tes diagnostik sekaligus sebagai tes formatif memberikan kemudahan bagi guru sehingga lebih efisien, dimana dinilai dari fungsi tes formatif yaitu dapat memberikan umpan balik dan tes diagnostik yaitu mengetahui kelemahan peserta didik secara individu yang dapat diketahui sekaligus dalam satu kali tes. Hasil dari tes yang didapatkan dari peserta didik dapat dilakukan penilaian tingkat ketuntasan belajar (mastery of learning) peserta didik [6]. Eksistensi tes diagnostik sebagai tes formatif yaitu dalam pembentukan kelompok heterogen yang dapat memecah ketegangan peserta didik untuk berdiskusi dalam kelompok [5].

Artikel ini bertujuan untuk mengidentifikasi pengaruh penggunaan tes diagnostik sebagai tes formatif dalam pembelajaran kimia. Hasil tinjauan dari beberapa studi literatur disusun penulis berupa artikel review yang membandingkan hasil penggunaan tes diagnostik sebagai tes formatif pada pembelajaran kimia. Pertanyaan penelitian yang akan dibahas pada artikel ini yaitu "bagaimana pengaruh penggunaan tes diagnostik sebagai tes formatif terhadap peningkatan ketuntasan belajar peserta didik?".

\section{METODE}

Berdasarkan tujuan tersebut, penulis melakukan uji statistik perbandingan hasil beberapa literatur penelitian yang seragam. Kemudian dilakukan analisis data dengan membandingankan menggunakan metode meta analisis yang dikaitkan dengan studi literatur. Metode meta analisis dilakukan dengan cara merangkum, mereview dan menganalisis data litearatur penelitian primer yang diolah secara statistik.

\section{LANDASAN TEORI}

\section{Kimia}

Kimia ialah ilmu yang mempelajari materi, yang meliputi sifat, susunan dan perubahannya, serta perubahan materi disertai perubahan energi [7]. Kimia merupakan salah satu rumpun pelajaran IPA yang memiliki tujuan memahami hukum, konsep, prinsip, teori kimia 
dan keterkaitannya serta penerapannya di kehidupan. [8]. Materi pelajaran kimia dapat disajikan secara kongkrit dan abstrak, sehingga penting bagi guru untuk menggunakan cara yang efektif untuk memahamkan peserta didik [9].

\section{Tes diagnostik}

Tes diagnostik digunakan untuk mendeteksi kekuatan dan kelemahan peserta didik [10]. Kelemahan peserta didik dapat berupa belumnya peserta didik menguasai materi prasyarat [11]. Hasil tes diagnostik dapat membantu guru dalam memberikan jenis bantuan yang sesuai dengan kesulitan yang dialami peserta didik [12]. Kesulitan belajar siswa dapat dilihat dari kemampuan peserta didik dalam memahami materi pembelajaran, mencapai indikator, menguasai soal pada level kognitifnya, dan observasi terhadap sikapnya di saat pembelajaran [13].

Penggunaan tes diagnostik dapat membantu memberikan informasi tingkat perkembangan aktual peserta didik secara individu [4]. Tes diagnostik memiliki karakteristik diantaranya yaitu: (1) Digunakan mendeteksi kesulitan belajar; (2) Dikembangkan berdasarkan sumber kesulitan; (3) Menggunakan bentuk soal jawaban singkat atau disertai pilihan alasan; (4) Disertai rancangan tindak lanjut, sesuai sumber kesulitan [14]. Penilaian diagnostik juga dapat memberikan peluang melakukan suatu proses pengujian untuk melayani satu tindakan tambahan selain tujuan-tujuan yang telah ditetapkan, dan dapat digunakan untuk mengintegrasikan proses pembelajaran dan penilaian [13]. Waktu pelaksanaan tes diagnostik yaitu disesuaikan dengan keperluan pembinaan dari suatu lembaga pendidikan untuk meningkatkan mutu pendidikan [15].

\section{Tes formatif}

Tes formatif adalah penilaian untuk memberikan umpan balik antara peserta didik dan guru dalam kegiatan pembelajaran [16]. Namun, efektivitas tes formatif bergantung pada isi umpan balik yang diberikan oleh guru secara berkelanjutan [17]. Hasil tes formatif bertujuan untuk memberikan informasi pada guru sejauh mana pemahaman peserta didik sesuai pencapaian hasil pembelajaran setiap kompetensi dasar yang telah ditentukan [18].

Karakteristik dari tes formatif diantaranya yaitu: (1) Dilakukan pada akhir setiap satuan pelajaran; (2) Digunakan untuk mengetahui seberapa jauh tujuan pembelajaran sudah tercapai; (3) Memberikan umpan balik perbaikan proses belajar mengajar; (4) Menggunakan tes hasil belajar/ kuesioner/ cara lain; (5) Penilaian penguasaan minimal $70 \%$ dari tujuan pembelajaran yang ingin dicapai [19]. Waktu pelaksanaan tes formatif yaitu pada akhir kegiatan pembelajaran dalam rencana pembelajaran [15].

\section{HASIL DAN PEMBAHASAN}

Pada artikel review yang dibuat bertujuan untuk mengetahui pengaruh penggunaan tes diagnostik sebagai tes formatif dalam pembelajaran kimia dengan membandingkan beberapa studi literatur penelitian. Asesmen diagnostik atau tes diagnostik merupakan pengukuran yang dapat memberikan peluang dalam proses pengujian dalam melayani satu tindakan tambahan selain tujuan yang telah ditetapkan, serta mengintegrasikan proses pembelajaran dan penilaian [14]. Terdapat 5 prinsip yang dimiliki asesmen diagnostik yaitu: (1) penggunaan tes diagnostik sebagai tes; (2) instrumen harus dirancang untuk memudahkan, diskrit, tepat sasaran, dan efisien dalam membantu guru untuk mendiagnosis; (3) penilaian tes diagnostik dalam prosesnya harus mencakup pemikiran pendidik maupun peserta didik; (4) idealnya mencakup penilaian diagnostik yaitu: observasi, penilaian awal, penggunaan media, tes, bantuan ahli, dan keputusan; (5) terdapat hubungan penilaian tes diagnostik terhadap perlakuan yang akan diberikan [14]. Pembuktian pengaruh penggunaan tes diagnostik sebagai tes formatif dilakukan dengan uji statistik sebelum penggunaan tes diagnostik dan sesudah terhadap ketuntasan belajar peserta didik. Pembuktian tersebut juga diperkuat dengan beberapa studi literatur yang mendukung.

$$
\text { Hasil analisis dilakukan dengan }
$$
membandingkan tiga artikel penelitian yang 
seragam untuk menunjukkan pengaruh tes diagnostik sebagai tes formatif dalam meningkatkan hasil belajar peserta didik. Tiga artikel yang digunakan sebagai perbandingan yaitu penelitian oleh Sitti Nurpaidah (2016) [5]; Sri Sulastri Yetti, Supriyati Gaguk, dan Margono (2019) [14]; dan Rinaningsih, Asep Kadarohman, Harry Firman \& Suyatno (2016) [20]. Hasil analisis pada pengolahan dan rangkuman data dipaparkan pada artikel secara deskriptif kualitatif dan kuantitatif. Presentase hasil sebelum dan sesudah penggunaan tes diagnostik sebagai tes formatif pada 3 artikel dapat diamati pada Tabel 1.

Tabel 1. Peningkatan Ketuntasan Belajar Peserta Didik

\begin{tabular}{|c|c|}
\hline Pengarang & Presentase Ketuntasan Belajar (\%) \\
\hline $\begin{array}{l}\text { Sebelum Penggunaan } \\
\text { Tes Diagnostik }\end{array}$ & $\begin{array}{l}\text { Sesudah Penggunaan } \\
\text { Tes Diagnostik }\end{array}$ \\
\hline $\begin{array}{l}\text { Sitti } \\
(2016)\end{array}$ & 26,85 \\
\hline $\begin{array}{l}\text { Sri Sulastri Yetti, } \\
\text { Supriyati Gaguk, } \\
\text { Margono (2019) } \\
\text { Rinaningsih, Asep } \\
\text { Kadarohman Harry } \\
\text { Firman \& Suyatno } \\
(2016)\end{array}$ & 77,5 \\
\hline Rata-Rata & 32,583 \\
\hline $\begin{array}{l}\text { Melalui Tabel } 1 \text { hasil presentase } \\
\text { ketuntasan belajar peserta didik pada tiga artikel } \\
\text { menunjukkan rata-rata presentase ketuntasan } \\
\text { belajar peserta didik sebelum menggunakan tes } \\
\text { diagnostik sebesar } 47,57 \% \text { dan sesudah } \\
\text { menggunakan tes diagnostik sebesar } 80,16 \% \text {. Hal } \\
\text { tersebut menunjukkan terjadinya peningkatan } \\
\text { rata-rata ketuntasan belajar peserta didik sebesar } \\
\text { 32,583\%. Peran tes diagnostik sebagai tes } \\
\text { formatif dapat membantu dalam meningkatkan } \\
\text { ketuntasan belajar peserta didik, selain itu juga } \\
\text { membantu guru dalam pemberian umpan balik } \\
\text { berupa pembentukan kelompok yang heterogen } \\
\text { agar terjadi pembelajaran yang efektif. } \\
\text { Tes diagnostik juga digunakan sebagai tes } \\
\text { formatif dimana dalam satu kali tes guru dapat } \\
\text { memberikan umpan balik dan mengetahui } \\
\text { kelemahan peserta didik secara individu [3]. } \\
\text { Pemberian umpan balik yaitu dengan melalui } \\
\text { analisis kelemahan peserta didik dalam } \\
\text { memahami beberapa indikator yang perlu } \\
\text { dilakukannya penekanan atau perbaikan. Tes } \\
\text { diagnostik sebagai tes formatif tidak digunakan } \\
\text { untuk menentukan grade dan apabila semakin } \\
\text { baik evaluasi diagnostiknya, maka semakin jelas }\end{array}$ & $\begin{array}{l}\text { pula tujuan pembelajaran yang } \\
\text { diterapkan. Tes diagnostik sebagai tes formatif } \\
\text { mempunyai penekanan khusus dalam } \\
\text { menyembuhkan kesulitan belajar peserta didik } \\
\text { [21]. } \\
\text { Melalui tes diagnostik yang digunakan } \\
\text { sebagai acuan dalam membantu pembelajaran } \\
\text { dapat memudahkan peserta didik dalam } \\
\text { memahami materi dengan bimbingan dari guru } \\
\text { serta temannya sendiri [5]. Penggunaan tes } \\
\text { diagnostik menjadikan peserta didik berfokus } \\
\text { pada kemampuan individual (pembelajaran } \\
\text { individual) [12]; [20]; [22]; [23]; [24]; [25]; [26]. } \\
\text { Pemanfaatan pembelajaran individual tidak dapat } \\
\text { terlepas dari pembentukan kelompok secara } \\
\text { heterogen. Pembentukan kelompok heterogen } \\
\text { yakni dengan memperhatikan kemampuan } \\
\text { akademis peserta didik. Kemajuan pembelajaran } \\
\text { dari penggunaan tes diagnostik dalam } \\
\text { pembelajaran sebagai pertimbangan pembentukan } \\
\text { kelompok heterogen dapat terlihat diantaranya } \\
\text { dari data presentase hasil ketuntasan belajar } \\
\text { peserta didik dilakukan analisis uji statistik tipe } \\
\text { paired sample, dan diperoleh hasil uji statistic } \\
\text { dapat diamati pada Tabel 2, Tabel 3, Tabel } 4 \text {. }\end{array}$ \\
\hline
\end{tabular}


Tabel 2. Paired Samples Statistics

Mean N Std. Deviation Std. Error Mean

\begin{tabular}{llllll}
\hline \multirow{2}{*}{ Pair 1} & Sebelum & 47,5767 & 3 & 6,27811 & 3,62467 \\
\cline { 2 - 5 } & Sesudah & 80,1600 & 3 & 2,30365 & 1,33001 \\
\hline
\end{tabular}

Tabel 3. Paired Samples Correlations

N Correlation Sig.

\begin{tabular}{lllll}
\hline Pair 1 & Sebelum \& Sesudah & 3 &, 282 &, 818 \\
\hline
\end{tabular}

Tabel 4. Paired Samples Test

Paired Differences

$\begin{array}{ccccccc}\text { Mean } & \begin{array}{c}\text { Std. } \\ \text { Deviation }\end{array} & \begin{array}{c}\text { Std. } \\ \text { Error } \\ \text { Mean }\end{array} & \begin{array}{c}\text { 95\% Confidence Interval } \\ \text { of the Difference }\end{array} & \text { T } & \text { df } & \begin{array}{c}\text { Sig. (2- } \\ \text { tailed) }\end{array}\end{array}$

\begin{tabular}{cccccccccc}
\hline Pair & Sebelum & - & 6,04614 & 3,49074 & $-47,60278$ & $-17,563888$ & $-9,334$ & 2 &, 011 \\
1 & $\begin{array}{c}\text { Sesudah } \\
\end{array}$ & 32,58333 & 6,040 & & & & &
\end{tabular}

Tabel 2 menunjukkan pengujian tes diagnostik sebagai tes formatif dari beberapa penelitian memiliki rata-rata ketuntasan belajar peserta didik sebelum menggunakan tes diagnostik sebesar 47,5767 dan mengalami peningkatan sesudah menggunakan tes diagnostik sebesar 80,1600. Sedangkan pada Tabel 3 menunjukkan angka korelasi nilai rata-rata sebelum dan sesudah menggunakan tes diagnostik sebagai tes formatif mencapai angka korelasi sebesar 0,282. Nilai signifikan sebelum dan sesudah penggunaan tes diagnostik pada Tabel 3 menghasilkan sebesar $(0,818)>\alpha(0,05)$ yang berarti tidak terdapat korelasi antara sebelum dan sesudah penggunaan tes diagnostik sebagai tes formatif. Adapun perhitungan uji hipotesis:

Uji hipotesis dapat disimpulkan apabila $\mathrm{H}_{0}=$ tidak terdapat perbedaan yang signifikan terhadap peningkatan hasil belajar peserta didik sebelum dan sesudah penggunaan tes diagnostik sebagai tes formatif, serta $\mathrm{H}_{1}=$ terdapat perbedaan yang signifikan terhadap hasil belajar peserta didik sebelum dan sesudah penggunaan tes diagnostik sebagai tes formatif.

Diketahui :

T hitung $=-9,334$

$\mathrm{Df}=2$

$\mathrm{Dk}=\mathrm{n}-\mathrm{k}$

$$
3-1=2
$$

Diasumsikan :

$\mathrm{T}$ hitung $<\mathrm{T}$ tabel, maka $\mathrm{H}_{0}=$ ditolak dan $\mathrm{H}_{1}=$ diterima

Ditanya :

T tabel?

Maka :

$$
\begin{aligned}
\mathrm{T} \text { tabel }= & 1-1 / 2 \times \alpha \\
& 1-1 / 2 \times(0,05) \\
& 1-0,025=0,975
\end{aligned}
$$

Setelah itu dicari besar nilai $\mathrm{T}$ tabel dengan t 0,975 dan dk 2 ditemukan nilai $\mathrm{T}$ tabel sebesar 4,303 [27]. Sehingga didapatkan hasil $\mathrm{T}$ hitung $(-9,334)<\mathrm{T}$ tabel $(4,303)$ sehingga $\mathrm{H}_{0}$ ditolak dan $\mathrm{H}_{1}$ diterima, maka terdapat perbedaan yang signifikan hasil belajar yang diperoleh 
peserta didik sebelum dan setelah penggunaan tes diagnostik sebagai tes formatif pada pembelajaran kimia.

Berdasarkan hasil olah data statistik dapat diketahui penggunaan tes diagnostik sebagai tes formatif untuk mengetahui kesulitan belajar mampu membantu guru dalam memberikan umpan balik. Informasi diagnostik peserta didik yang didapatkan guru akan mengajak peserta didik berperan aktif untuk meningkatkan kegiatan pembelajaran [28]. Jenis diagnostik ini berfokus pada proses pembelajaran, sehingga penerapan tes diagnostik tersebut hampir sama seperti penilaian formatif.

Guru menggunakan penilaian untuk merencanakan proses pembelajaran, tetapi penilaian harus tetap terpisah dari proses pembelajaran, sehingga siswa menganggap diagnosis sebagai bagian dari dukungan atau proses pembelajaran [29]. Dukungan tersebut ditunjukkan dengan meningkatnya hasil belajar peserta didik dengan memberikan umpan balik berupa mempertimbangkan tes diagnostik sebagai tes formatif dalam pembentukan kelompok yang heterogen. Kelanjutan dari pengunaan tes diagnostik sebagai tes formatif dalam pembentukan kelompok heterogen dapat memberikan peserta didik kesempatan saling mengajar dan saling mendukung serta meningkatkan relasi dan interaksi antara ras, etnik, dan jenis kelamin [4].

Namun, pengajaran secara heterogen dalam kelas dinilai sulit. Tantangan utama dalam pengajaran secara heterogen yaitu penyesuaian instruksi dengan kebutuhan individu setiap peserta didik. Penggunaan tes diagnostik sebagai tes formatif dapat membantu dengan memberikan informasi tingkat perkembangan aktual peserta didik [30].

Dukungan tes diagnostik memfokuskan pada personalisasi pembelajaran, yaitu pengajaran dengan menyesuaikan kebutuhan peserta didik secara individu. Pemanfaatan tes diagnostik yakni sebagai instrumen yang diasumsikan lebih baik. Hal tersebut dikarenakan tes diagnostik sebagai tes formatif memanfaatkan pengamatan secara subjektif, sehingga diharapkan menjadikan pengajaran lebih baik [30].

\section{SIMPULAN}

Simpulan yang dapat diambil yaitu eksistensi tes diagnostik sebagai tes formatif dapat meningkatkan kemampuan belajar peserta didik. Penggunaan tes diagnostik sebagai tes formatif dapat dijadikan pertimbangan pada pembelajaran kimia dalam pembentukan kelompok heterogen. Hasil belajar menunjukkan tersebut menghasilkan peningkatan paling rendah sebesar $26,85 \%$ dan peningkatan paling tinggi sebesar $38,9 \%$, serta peningkatan signifikan sebesar 32,583\%.

\section{DAFTAR PUSTAKA}

1. Yakubi, Malik., Zulfadli., Latifah Hanum. 2017. Menganalisis Tingkat Pemahaman Siswa pada Materi Ikatan Kimia Menggunakan Instrumen Penilaian Four-Tier Multiple Choice (Studi Kasus pada Siswa Kelas X SMA Negeri 4 Banda Aceh). Jurnal Ilmiah Mahasiswa Pendidikan Kimia (JIMPK)., Vol 2, No 1, pp. 19-26.

2. Langitasari, I. 2016. Analisis Kemampuan Awal Multi Level Representasi Mahasiswa Tingkat I pada Konsep Reaksi Redoks. EduChemia (Jurnal Kimia dan Pendidikan.)., Vol 1, No 1, pp. 14-24.

3. Utari, D., Noor F \& Lisa T. 2017. Kemampuan Representasi Siswa pada Materi Kesetimbangan Kimia Menggunakan Animasi Berbasis Representasi Kimia. Jurnal Pendidikan dan Pembelajaran Kimia., Vol 6, No 3, pp. 414-426.

4. Csapó, B., Gyöngyvér M. 2019. Online Diagnostic Assessment in Support of Personalized Teaching and Learning: The eDia System. Journal Frontiers in Psychology., Vol 10, No 1522, pp. 1-14.

5. Nurpaidah, Sitti. 2016. Peningkatan Kualitas Hasil Belajar Kimia (Oksidasi Reduksi) pada Siswa Kelas X SMA Negeri 3 Watampone Melalui Pembelajaran Remedial dengan Tutor Sebaya. Jurnal Chemica., Vol 17, No 1, pp. 34-43.

6. Anggraeni, H B., Bambang S \& Rizka A P. 2017. Pengembangan Tes Formatif yang Berfungsi sebagai Tes Diagnostik Kesulitan 
Belajar Pokok Bahasan Animalia. Jurnal Prodi Pendidikan Biologi., Vol 6, No 6, pp. 341-350.

7. Rahmawati, Y. 2018. Peran Transformative Learning dalam Pendidikan Kimia: Pengembangan Karakter, Identitas Budaya, dan Kompetensi Abad ke-21. Jurnal Riset Pendidikan Kimia., Vol 8, No 1, pp. 1-16.

8. Fahmawati, D. 2018. Pengembangan Model Pembelajaran "GREATER" pada Pembelajaran Kimia sebagai Upaya Penanaman Literasi Sains Peserta Didik. Jurnal THABIE., Vol 1, No 1, pp. 44-52.

9. Juniarni, D I., Raudhatul F \& Rizmahardian A K. 2019. Pengembangan Permainan Lego Kimia sebagai Media Pembelajaran Sub Materi Konfigurasi Elektron pada Siswa Kelas X SMA Muhammadyah 1 Pontianak. Ar-Razi Jurnal Ilmiah., Vol 7, No 1, pp. 47-55.

10.Shim, G T G., Abang M H A S \& Farah L A. 2017. Relationship between Students' Diagnostic Assessment and chievement in a Pre-University Mathematics Course. Journal of Education and Learning., Vol 6, No 4, pp. 364-371.

11.Prihatni, Y., Kumaidi., Mundilarto. 2016. Pengembangan Instrumen Diagnostik Kognitif pada Mata Pelajaran IPA di SMP. Jurnal Penelitian dan Evaluasi Pendidikan., Vol 20, No 1, pp. 111-125.

12.Santoso, S., Rinaningsih. 2013. Pengembangan Tes untuk Menganalisis Ketuntasan Hasil Belajar Siswa SMA Kelas XI. Journal of Chemical Education., Vol 2, No 2, pp. 204210.

13.Nursalam. 2016. Diagnostik Kesulitan Belajar Matematika: Studi pada Siswa SD/MI di Kota Makassar. Jurnal Ilmu Tarbiyah dan Keguruan Lentera Pendidikan., Vol 19, No 1, pp. 1-15.

14.Sulastri, Sri., Yetti Supriyati., Gaguk Margono. 2019. Peningkatan Hasil Belajar Siswa Melalui Asesmen Diagnostik dalam Pembelajaran Lintas Minat. Prosiding Seminar Nasional Pendidikan KALUNI., Vol 2, pp. 722-733.

15.Sawaluddin. 2018. Konsep Evaluasi dalam Pembelajaran Pendidikan Islam. Jurnal AlThariqah., Vol 3, No 1, pp. 39-53.

16.Nurjannah. 2017. Efektivitas Bentuk Penilaian Formatif Disesuaikan dengan Media Pembelajaran. Jurnal Parameter., Vol 29, No 1, pp. 75-90.
17. Voinea, Lucian. 2018. Formative Assessment as Assessment for Learning Development. Journal of Pedagogy., Vol 1, pp. 7-23.

18.Wijaya, K R. 2017. Kontribusi Bentuk Tes Formatif dan Gaya Belajar terhadap Hasil Belajar IPS. Jurnal Penelitian dan Penilaian Pendidikan., Vol 2, No 2, pp. 158-174.

19.Rohayati, I., Nonoh S A., Elvin Y E. 2013. Penyusuan Instrumen Tes Formatif Fisika SMP. Jurnal Pendidikan Fisika., Vol 1, No 1, pp. 46-54.

20.Rinaningsih., Asep K., Harry F \& Suyatno. 2016. Penerapan Metode Pembelajaran Pondok Pesantren dalam Perkuliahan Kimia Organik Materi Mekanisme Reaksi $\mathrm{S}_{\mathrm{N}} 1$ dan $\mathrm{S}_{\mathrm{N}} 2$. Prosiding Seminar Nasional Kimia dan Pembelajarannya., Surabaya: 17 September 2016. pp. 104-107.

21.Yasir, I. 2016. Evaluasi Diagnostik dan Remedial oleh Guru dalam Proses Pembelajaran. Jurnal BAPPEDA., Vol 2, No 3, pp. 186-192.

22.Saidah, K N., Rinaningsih. 2012. Pengembangan Tes Diagnostik dengan Menggunakan PHP-MySQL pada Materi Pokok Laju Reaksi untuk SMA Kelas XI. Unesa Journal of Chemical Education., Vol 1, No 1, pp. 145-153.

23.Wardhani, A A., Rinaningsih. 2012. Pengembangan Tes Diagnostik Berbasis Komputer Menggunakan Program PHP MySQL pada Materi Pokok Kesetimbangan Kimia SMA Kelas XI. Unesa Journal of Chemical Education., Vol 1, No 1, pp. 25-34.

24.Putri, K P., Rinaningsih. 2013. Pengembangan Tes Diagnostik Materi Teori Mekanika Kuantum dan Ikatan Kimia. Unesa Journal of Chemical Education., Vol 2, No 2, pp. 159172.

25.Qonitatillah., Rinaningsih. 2014. Pengembangan Tes Diagnostik Materi Struktur Atom, Bentuk Molekul, dan Gaya Antar Molekul. Unesa Journal of Chemical Education., Vol 3, No 1, pp. 54-60.

26. Maharani, C K., Rinaningsih. 2015. Pengembangan Tes Diagnostik dalam Media Cetak Teks Terprograma pada Materi Pokok Laju Reaksi. Unesa Journal of Chemical Education., Vol 4, No 1, pp. 90-98. 
27.Sudjana. 1996. Metode Statistika. Bandung: Tarsito.

28.Zhao, Z. 2013. An Overview of Studieson Diagnostic Testing and its Implications for the Development of Diagnostic Speaking Test. International Journal of English Linguistics., Vol 3, No 1, pp. 41-45.

29. Tolsdorf, Yannik., Silvija Markic. 2017. Exploring Chemistry Student Teachers'
Diagnostic Competence- A Qualitative CrossLevel Study. Journal Education., Vol 7, No 4, pp. 86-99.

30.Purba, Azrina. Penerapan Pembelajaran Kooperatif dengan Pendekatan Struktural TPS dan TSTS untuk Meningkatkan Hasil Belajar Matematika Siswa Kelas X5 SMA Negeri 1 Tambang. MES (Journal of Mathematics Education and Science)., Vol 2, No 1, pp. 2432. 